\title{
A New Model of the Oceanic Evaporation Duct
}

\author{
STEVEN M. BABIN \\ The Johns Hopkins University Applied Physics Laboratory, Laurel, Maryland \\ GeORGe S. Young \\ Department of Meteorology, The Pennsylvania State University, University Park, Pennsylvania \\ JAMES A. CARTON \\ Department of Meteorology, University of Maryland, College Park, Maryland \\ (Manuscript received 8 February 1996, in final form 6 July 1996)
}

\begin{abstract}
Failure to consider anomalous propagation of microwave radiation in the troposphere may result in erroneous meteorological radar measurements. The most commonly occurring anomalous propagation phenomenon over the ocean is the evaporation duct. The height of this duct is dependent on atmospheric variables and is a major input to microwave propagation prediction models. This evaporation duct height is determined from an evaporation duct model using bulk measurements. Two current evaporation duct models in widespread operational use are examined. We propose and test a new model that addresses deficiencies in these two models. The new model uses recently refined bulk similarity expressions developed for the determination of the ocean surface energy budget in the Tropical Ocean Global Atmosphere Coupled Ocean-Atmosphere Response Experiment. Comparison of these models is made using data collected from a boat off Wallops Island, Virginia, during a range of seasons and weather conditions and from the tidal Potomac River during June and August. Independent evaporation duct height determinations are made using profile measurements from the same boat and are corroborated with fade measurements made with a nearby microwave link whenever possible. The proposed model performs better than the other (operational) models for the cases examined and has advantages of internal consistency.
\end{abstract}

\section{Introduction}

Nonstandard refraction (anomalous propagation) of electromagnetic radiation in the lower troposphere may cause radio or radar signals to propagate so that the curvature of their path is greater than the earth's surface curvature. These microwaves may then become trapped within this ducting layer and travel beyond the horizon. With the development of quantitative radar rainfall estimates, failure to recognize the effects of anomalous propagation may lead to forecasting errors (Moszkowicz et al. 1994). Borsum (1995) describes a case in which anomalous propagation conditions resulted in a Doppler radar echo from a 2400-m mountain being attributed to nonexistent thunderclouds with tops of $11000 \mathrm{~m}$ and containing velocities as high as $18 \mathrm{~m} \mathrm{~s}^{-1}$. This echo persisted at radar elevation angles up to $3.5^{\circ}$. Babin (1995) presented case studies of synoptic conditions as-

Corresponding author address: Dr. Steven M. Babin, Applied Physics Laboratory, The Johns Hopkins University, Johns Hopkins Road, Laurel, MD 20723-6099.

E-mail: Steven.Babin@jhuapl.edu sociated with nonstandard refraction. Over the ocean, the most common type of anomalous propagation is due to a phenomenon called the evaporation duct.

Propagation of microwave and millimeter-wave electromagnetic radiation in the atmosphere is determined by gradients of the refractive index of air. Because it is very close to unity, this refractive index $n$ is represented by a scaled quantity called the radio refractivity $N$. Debye (1929) theory has been used to express the refractivity $N$ in terms of atmospheric pressure, water vapor pressure, and temperature (Bean and Dutton 1968). These expressions are given by

$$
N=(n-1) \times 10^{6}=\frac{77.6}{T}\left(p+\frac{4810 e}{T}\right),
$$

where $T(\mathrm{~K})$ is the atmospheric temperature, $p(\mathrm{hPa})$ is the total atmospheric pressure, and $e(\mathrm{hPa})$ is the water vapor pressure. The constants are empirically derived from dielectric constant measurements and are valid for radio frequencies between 1 and $100 \mathrm{GHz}$. Modified refractivity $M$, which takes the earth's curvature into account, is related to radio refractivity $N$ by 


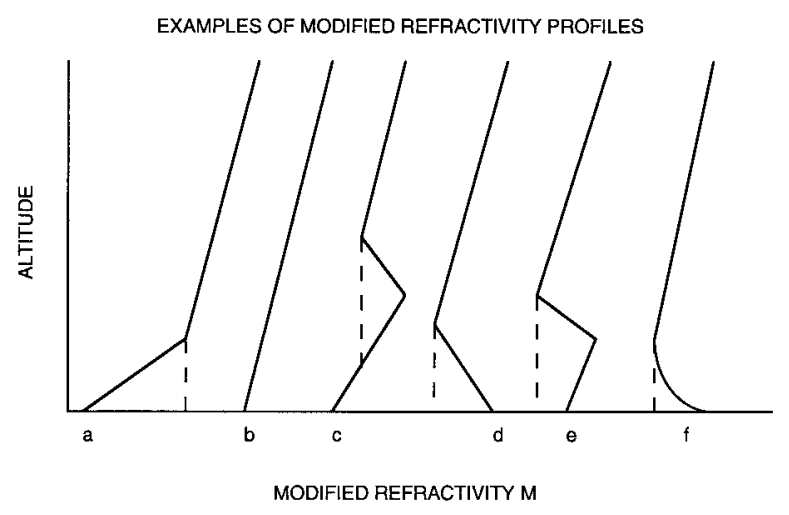

FIG. 1. Plots of modified refractivity $M$ versus altitude: (a) subrefractive layer denoted by dashed line; (b) normal refraction; (c) elevated duct denoted by dashed line; (d) surface duct denoted by dashed line; (e) surface duct (dashed line) due to elevated region of strongly negative vertical $M$ gradient; (f) evaporation duct denoted by dashed line.

$$
M=N+\frac{z}{10^{-6} r_{e}} \approx N+0.157 z
$$

where $r_{e}$ is the earth's radius and $z$ is altitude in meters.

Microwave propagation conditions are categorized using the gradient of refractivity with respect to altitude (Almond and Clarke 1983). These categories include normal refraction, superrefraction, or subrefraction, referring to normal, better than normal, or worse than normal propagation, respectively. When $\partial N / \partial z$ is equal to or more negative than $-0.157 \mathrm{~m}^{-1}$, microwaves are refracted down toward the earth's surface. If this gradient extends to the earth's surface or is very strong, microwaves originating within this layer will become trapped and propagate along the surface. This layer behaves like a waveguide and can lead to propagation over the horizon. This is a type of superrefractive condition known as a surface duct. The height of the duct is defined as the height at which $\partial N / \partial z$ is $-0.157 \mathrm{~m}^{-1}$ or, equivalently, the height for which $M$ is a minimum. An example of a very deep surface duct caused by Santa Ana conditions off the coast of California is described in Babin and Rowland (1992). A climatology of surface duct conditions for Wallops Island, Virginia, is presented in Babin (1996a). Examples of refractivity classification using $M$ profiles are given in Fig. 1 .

Evaporation ducts are a subset of surface ducts and are formed just above the ocean surface by strong vertical humidity gradients (Cook 1991). Evaporation ducts are almost always present, yet their heights are highly variable in space and time. The effects of the evaporation duct on microwave propagation have long been recognized (Katzin et al. 1947; Anderson and Gossard 1953a,b). For example, if a transmitter is located below the height of the evaporation duct, it may be able to communicate over the horizon with a receiver that is also located within this duct. However, if the receiver is located instead above the height of the duct, it may have difficulty receiving the transmitted signal, even at ranges within the normal radio horizon. In a similar manner, ducting may significantly affect the performance of surface surveillance radars. The various effects of the evaporation duct on radar and communications have been discussed by Reilly and Dockery (1990), Paulus (1990), Hitney and Vieth (1990), Anderson (1989, 1990), and Douchin et al. (1994).

Microwave propagation models, such as the Tropospheric Electromagnetic Parabolic Equation Routine (TEMPER) and the Integrated Refractive Effects Prediction System (IREPS), are used to predict radar and communications performance for a given set of conditions (Dockery 1988; Baumgartner et al. 1983). Vertical profiles of refractivity are required for input to these models. Because such profiles are very difficult to measure routinely close to the ocean surface, evaporation duct models were developed that use bulk atmospheric measurements at a single altitude (e.g., the height of the deck of a ship) to determine the evaporation duct height. When applying electromagnetic propagation models such as TEMPER or IREPS, this evaporation duct height is used to create a low-altitude refractivity profile that is blended with refractivity data measured at higher altitudes (e.g., radiosonde data). The height of the evaporation duct is a critical parameter for determining the low altitude refractivity profiles. Konstanzer (1994) showed that, for the TEMPER model, it is necessary to have the evaporation duct height determined to within $2 \mathrm{~m}$ in order to avoid the possibility of considerable errors in propagation prediction.

This paper presents a new model for determining the height of the evaporation duct in the marine boundary layer and compares this model to current operational models and to independent observations. Current evaporation duct models rely heavily on empirical relationships to increase computational speed, rather than solving the more difficult implicit similarity equations. The current availability of high-speed desktop computers has made it possible to incorporate more boundary layer physics and decrease the use of empirical relationships. The new model described in this paper takes advantage of this evolution in technology and also incorporates recent advances in the characterization of the marine boundary layer made as part of the Tropical Ocean Global Atmosphere Coupled Ocean-Atmosphere Response Experiment (TOGA COARE). Our model also provides not only evaporation duct height, but all the information necessary to generate an entire low-altitude refractivity profile. Therefore, our model is easily integrated to provide entire low-altitude refractivity profiles (Babin 1996b) for input into any present or future electromagnetic propagation model. This paper will examine how well the evaporation duct models predict the height of the evaporation duct since that has been the standard for their evaluation in the past (Patterson 1985; Paulus 1985; Musson-Genon et al. 1992). 


\section{Evaporation duct models}

The general approach for all evaporation duct models involves finding an expression for the vertical refractivity gradient in terms of atmospheric variables. This expression is then solved for duct height given a fixed value of the critical refractivity gradient for ducting. Because the evaporation duct is limited to the surface layer, a similarity theory such as that of Monin and Obukhov (1954) is useful for deriving this expression. All of the evaporation duct models discussed here use some form of Monin-Obukhov similarity theory. However, these models differ significantly in the way this theory is applied.

\section{a. Paulus-Jeske (PJ) model}

The PJ model (Jeske 1973; Paulus 1984, 1985, 1989) has been perhaps the most successful and widely used evaporation duct model. It has been incorporated into the IREPS microwave propagation prediction model that has been in operational use by the U.S. Navy since 1978 (Baumgartner et al. 1983; Hitney and Richter 1976). The PJ model uses air temperature, relative humidity, and wind speed at $6 \mathrm{~m}$, and sea surface temperature as inputs, but assumes a constant surface atmospheric pressure of $1000 \mathrm{hPa}$.

The PJ model uses a quantity called potential refractivity instead of radio refractivity. Potential refractivity is simply the radio refractivity given in Eq. (1) using $1000 \mathrm{hPa}$ for the pressure, potential temperature instead of ordinary temperature, and potential water vapor pressure instead of ordinary water vapor pressure. Jeske (1973) based this choice on the hypothesis that potential refractivity is a conservative property and behaves as a similarity variable. Therefore, this model uses a similarity expression for the vertical slope of potential refractivity. This expression is then solved for the duct height given the critical gradient of potential refractivity for ducting. Cook and Burk (1992) later showed that, under stable conditions, potential refractivity did not obey Monin-Obukhov similarity theory because, when properly nondimensionalized, the vertical gradient of potential refractivity was not a single universal function of $z / L$ (where $L$ is the Obukhov length). Therefore, an underlying assumption of this model is likely in error, at least for stable conditions.

To calculate potential refractivity, the PJ model assumes that potential temperature and potential water vapor pressure are equal to their ordinary nonpotential counterparts. Therefore, this model approximates potential refractivity by using Eq. (1) with $p=1000 \mathrm{hPa}$, giving essentially the same result as nonpotential refractivity. However, the PJ model does not use the critical gradient for nonpotential refractivity $(-0.157)$ to determine duct height. Instead, the PJ model uses a critical potential refractivity gradient of -0.125 . Therefore, the PJ model is using nonpotential refractivity to eval- uate a gradient for comparison with a fixed value based on potential refractivity. This is an important discrepancy since it represents a change in the criteria for the occurrence of ducting.

Paulus (1989) derives the critical potential refractivity gradient for ducting as follows.

$$
\frac{\partial N_{p}}{\partial z}=\frac{\partial N}{\partial z}-\frac{\partial N}{\partial p} \frac{\partial p}{\partial z},
$$

where $N_{p}$ is the potential refractivity and $N$ is the nonpotential refractivity. The term $\partial N / \partial z$ is set to the critical gradient of -0.157 for ducting. Because the term $\partial N /$ $\partial p$ varies only by $0.02 \mathrm{hPa}^{-1}$ over the temperature range of $0^{\circ}-30^{\circ} \mathrm{C}$, Paulus chooses a value of $0.27 \mathrm{hPa}^{-1}$. Using the hydrostatic relationship and the ideal gas law, Paulus assumes a "standard" air temperature of $15^{\circ} \mathrm{C}$ to obtain $\partial p / \partial z=-0.12$. When these values are used, the critical potential refractivity gradient for ducting is -0.125 .

The PJ model uses the bulk Richardson number to categorize atmospheric stability and to estimate the Obukhov length. The bulk Richardson number is often defined in terms of virtual potential temperature (Stull 1991), especially over the ocean (Brutsaert 1991). As will be shown later, the specific humidity contribution to the virtual potential temperature can be significant enough to change the sign of the Richardson number and therefore the stability criteria used in the PJ model. However, the PJ model uses ordinary nonpotential temperatures to calculate the bulk Richardson number.

For stable or neutral conditions, if the calculated duct height is negative or if it is greater than the estimated Obukhov length $L$, the PJ model assumes that this estimated Obukhov length is in error. Instead of using this estimated Obukhov length in the duct height calculation, the PJ model substitutes the duct height variable for the estimated Obukhov length in the PJ model's duct height equation and solves for the duct height again (Paulus 1989). Paulus explains the reasoning for this procedure by stating that the ratio of duct height to estimated Obukhov length should never exceed unity. While the evaporation duct height certainly has some relation to the Obukhov length, there is no physical reason for the evaporation duct height never to exceed it. Furthermore, if the calculated duct height is negative, perhaps it would be better to set it to zero instead.

The PJ model assumes a constant aerodynamic roughness length. However, aerodynamic roughness lengths can vary by two orders of magnitude, depending upon sea state, wind speed, wave age, and wave steepness (Stull 1991; Hsu 1988). Instead of assuming the aerodynamic roughness length to be constant, it would be more accurate to determine it from the input atmospheric variables as was done by Fairall et al. (1996).

A slight change in the water vapor pressure gradient could significantly impact the determination of the height of the critical refractivity gradient for ducting. Therefore, the best available equation for saturation va- 
por pressure should be used. The PJ model uses the equation of Kiefer (1941) to calculate saturation vapor pressure. Buck (1981) provides equations that are based on more recent experimental studies and therefore are probably more accurate. Also, the PJ model does not use the salinity correction suggested by Sverdrup et al. (1942) for the calculation of saturation water vapor pressure.

Paulus $(1984,1985)$ states that stable conditions and relative humidities in the range of $65 \%-75 \%$ measured aboard ship would not be expected in the open ocean. Paulus finds that his model may give "unreasonably" high evaporation duct heights under these conditions. This result may be due to the use of ordinary temperature instead of virtual temperature in the calculation of bulk Richardson number. However, Paulus $(1984,1985)$ attributed this result to measurement error and compensated for it by applying an ad hoc temperature correction when the air temperature minus the sea surface temperature is algebraically greater than $-1 \mathrm{~K}$. Although air-sea temperature differences greater than $-1 \mathrm{~K}$ may be infrequent over the open ocean, they may occur more commonly in coastal areas, especially when warm dry air is being advected from land.

Finally, the PJ model restricts duct heights from exceeding $40 \mathrm{~m}$. Instead, it might be better if the model equations obtained heights greater than $40 \mathrm{~m}$ only on the rare occasions when they do occur. To examine the effects of these last two features of the PJ model, a modified version of the PJ model (called the Jeske or J model) was tested that removed them.

\section{b. Musson-Genon-Gauthier-Bruth (MGB) model}

Musson-Genon et al. (1992) described an evaporation duct model that used the air temperature, pressure, relative humidity, and wind speed at a known measurement height, and the sea surface temperature as inputs. Using Eq. (1), $\partial N / \partial z$ is expressed in terms of vertical gradients of pressure, temperature, and moisture. This equation can then be solved for the duct height $z$ by substituting the critical value of $\partial N / \partial z$ for ducting $(-0.157)$ and using expressions for the vertical gradients of pressure, temperature, and moisture. The hydrostatic approximation is used to calculate the vertical pressure gradient. Monin-Obukhov similarity expressions are used for the vertical gradients of temperature and moisture.

Musson-Genon et al. (1992) presented an iterative and an analytic version of their model. When the $\phi$ functions (nondimensional Monin-Obukhov similarity profiles for temperature and moisture) of Businger et al. (1971) were used in their iterative version, the results were the same as their analytic version for the unstable case but significantly different for the stable case. If, instead, their iterative version used Wieringa's (1980) $\phi$ functions, the results of the analytic and iterative versions were in agreement for stable and unstable cases. Therefore, the authors recommended using the analytic meth- od to obtain the most accurate evaporation duct height. If the iterative method were to be used instead, then they recommended using Wieringa's corrections to get the same results as their analytic version. However, there was some controversy concerning Wieringa's corrections to the Businger formulations of these $\phi$ functions (Wyngaard et al. 1982; Wieringa 1982; Kaimal and Wyngaard 1990). Therefore, the findings of MussonGenon et al. that their analytic and iterative versions agree only when Wieringa's $\phi$ functions are used may be subject to this same controversy and may possibly indicate problems with their model. In their analytic version, the method of Geleyn (1988) is used to provide $\phi$ functions whose forms are such that an analytical solution is possible. These functions were incorporated into the European Centre for Medium-Range Weather Forecasts (ECMWF) model in 1987. Because their analytic method is recommended for the best results and is used in the operational numerical weather prediction models of Météo-France and ECMWF, that is the method used in this paper for comparison with other models.

While the PJ model uses an explicit relationship between the Obukhov length and the bulk Richardson number, the MGB model uses an implicit relationship suggested by Louis (1979) and based on experimental data taken over the Norwegian Sea. On theoretical grounds, the MGB model adheres to Monin-Obukhov similarity theory more faithfully than the PJ model. However, neither model provides a means of extending Monin-Obukhov similarity theory to very low wind speeds (Stull 1991).

\section{c. The proposed model (model A)}

Both the PJ and MGB models rely on empirically derived relationships between the Richardson number and Obukhov length to decrease computation time. However, with high speed computing now available at the desktop, it is appropriate to replace empirical relationships with boundary layer physics wherever possible. Model A addresses the problems mentioned above and is somewhat similar in approach to a model described by Fairall et al. (1978). Unlike the PJ model, the Fairall model explicitly calculated the bulk transfer coefficients from bulk measurements. These coefficients were used to calculate temperature and moisture fluxes by means of a nondimensional Monin-Obukhov similarity profile. These fluxes were then used to calculate implicitly the duct height through an iterative procedure. However, Patterson (1985) compared Fairall's model with the PJ model and found that the latter was a better predictor of evaporation duct height. The new model described here uses the results of more recent bulk algorithm studies (Liu et al. 1979; Fairall et al. 1996) unavailable to Fairall in 1978.

In their efforts to characterize the surface energy budget with unprecedented accuracy, the TOGA COARE investigators developed and refined many techniques for 
more accurately determining various Monin-Obukhov parameters needed by model A (Fairall et al. 1996). The equations of Buck (1981) and a salinity correction (Sverdrup et al. 1942) were used to calculate saturation water vapor pressures accurately. The technique of Godfrey and Beljaars (1991) was used to extend the validity of Monin-Obukhov theory to low wind speeds. The surface-layer theory of Liu et al. (1979) was used to determine Monin-Obukhov parameters. These techniques were verified by simultaneous flux and bulk measurements made from numerous ships, buoys, and aircraft (Webster and Lukas 1992; Fairall et al. 1996). Our new evaporation duct model incorporates many of these advances as well as other modifications and thus is more consistent with current theoretical understanding than current models. This new model is described briefly below and in detail in Babin (1996b).

Unlike the PJ model, our model uses nonpotential refractivity as the critical gradient for ducting. While nonpotential refractivity is not a conservative property that can be used as a similarity variable, this fact is not an assumption of our model and therefore poses no problems for our model. Instead, our model assumes only Monin-Obukhov similarity for potential temperature and specific humidity within the surface layer. To solve for the critical slope of $\partial N / \partial z$ for ducting, Eq. (1) is rewritten in terms of specific humidity $q$ and potential temperature $\theta$. Then $\partial N / \partial z$ is derived in terms of $\partial p / \partial z$, $\partial \theta / \partial z$, and $\partial q / \partial z$. The hydrostatic assumption is used to evaluate $\partial p / \partial z$. The following definition of specific humidity is used (Rogers and Yau 1989).

$$
q=\frac{\epsilon e}{p-(1-\epsilon) e}
$$

where $e$ is the water vapor pressure, $p$ is the atmospheric pressure, and $\epsilon=0.62197$. We then have

$$
\frac{\partial N}{\partial z}=A+B \frac{\partial \theta}{\partial z}+C \frac{\partial q}{\partial z}
$$

where

$$
\begin{aligned}
A= & -\left(0.01 \mathrm{hPa} \mathrm{kg}^{-1} \mathrm{~m} \mathrm{~s}^{2}\right) \\
& \times \rho_{a} g\left\{\frac{77.6}{T}+\frac{4810 \times 77.6 q}{T^{2}[\epsilon+(1-\epsilon) q]}\right\} \\
& -\frac{g[p-(1-\epsilon) e]}{c_{p a}}\left\{\frac{-77.6}{T^{2}}-\frac{2 \times 4810 \times 77.6 q}{T^{3}[\epsilon+(1-\epsilon) q]}\right\}
\end{aligned}
$$

and

$$
B=\left(\frac{p}{1000}\right)^{R_{a} / c_{p a}}\left\{\frac{-77.6 p}{T^{2}}-\frac{2 \times 4810 \times 77.6 q p}{T^{3}[\epsilon+(1-\epsilon) q]}\right\}
$$

and

$$
C=\frac{4810 \times 77.6 p \epsilon}{T^{2}[\epsilon+(1-\epsilon) q]^{2}} .
$$

In these expressions, $T(\mathrm{~K})$ is the atmospheric temperature, $p(\mathrm{hPa})$ is the atmospheric pressure, $\rho_{a}\left(\mathrm{~kg} \mathrm{~m}^{-3}\right)$ is the air density, $g\left(\mathrm{~m} \mathrm{~s}^{-2}\right)$ is the gravitational acceleration, $c_{p a}\left(\mathrm{~J} \mathrm{~kg}^{-1} \mathrm{~K}^{-1}\right)$ is the dry-air specific heat, and $R_{a}\left(\mathrm{~J} \mathrm{~kg}^{-1} \mathrm{~K}^{-1}\right)$ is the dry-air gas constant. Note that the constant 0.01 in the expression for $A$ is necessary to convert from pascals to hectopascals in order to make the units for the constants in Eq. (1) (which are in terms of hectopascals) compatible with the units for air density and gravitational acceleration.

Monin-Obukhov similarity theory is used to evaluate $\partial \theta / \partial z$ and $\partial q / \partial z$ from

$$
\begin{aligned}
& \frac{\partial \theta}{\partial z}=\frac{\theta_{*} \phi_{t}}{\kappa z} \\
& \frac{\partial q}{\partial z}=\frac{q_{*} \phi_{t}}{\kappa z}
\end{aligned}
$$

where $\theta_{*}$ and $q_{*}$ are the Monin-Obukhov scaling parameters, $\phi_{t}$ is the nondimensional Monin-Obukhov profile for both temperature and moisture, and $\kappa$ is von Kármán's constant (0.4).

To determine $\theta_{*}, q_{*}$, and $\phi_{t}$, a modified version of the TOGA COARE bulk flux algorithm is used. This algorithm is described in detail by Fairall et al. (1996) and is available via the World Wide Web at http:// www.coaps.fsu.edu:80/coare/flux_algor/.

Following Liu et al. (1979), initial estimates of the Monin-Obukhov scaling parameters are made assuming neutral stability. Then an iterative procedure is used to obtain their nonneutral values. Whereas Fairall et al. (1996) fixed the number of iterations at 20, Model A continues the iterations until the new Monin-Obukhov parameters are within $0.001 \%$ of their previous values (Babin 1996b). This convergence typically takes less than 20 iterations.

These final estimates of the Monin-Obukhov parameters are used to determine the evaporation duct height as follows. For stable and neutral conditions, Eq. (5) is solved for the duct height $z_{d}$ by substituting $\partial N / \partial z=$ -0.157 and solving analytically to obtain

$$
z_{d}=\frac{-\left(B \theta_{*}+C q_{*}\right)}{\kappa(A+0.157)+\frac{5}{L}\left(B \theta_{*}+C q_{*}\right)} .
$$

For unstable conditions, the functional form of $\phi_{t}$ is such that the following must be solved iteratively,

$$
z_{d}=\frac{-\left(B \theta_{*}+C q_{*}\right) \phi_{t}}{\kappa(A+0.157)},
$$

since $\phi_{t}$ is a function of $z_{d} / L$. The iteration continues until the new value of $z_{d}$ is within $0.0001 \mathrm{~m}$ of the old value (typically less than 20 iterations).

As an example calculation, assume that the measure- 
ment height is $6 \mathrm{~m}$, the air temperature is $1.6^{\circ} \mathrm{C}$, the sea surface temperature is $2.2^{\circ} \mathrm{C}$, the relative humidity is $73.3 \%$, the wind speed is $4.6 \mathrm{~m} \mathrm{~s}^{-1}$, and the atmospheric pressure is $1024.15 \mathrm{hPa}$. Model A gives a duct height of $4.5 \mathrm{~m}$. In addition to calculating the duct height, a modified version of the Monte Carlo procedure described in section 4a below has been incorporated into model A to provide an error estimate. This procedure randomly varies the sensor inputs such that the mean is the measured value and the standard deviation is the sensor accuracy (input by the user). For 300 such randomly varying runs, the standard deviation in the resulting duct height provides an error estimate. For this set of measurement inputs, this error estimate is $1 \mathrm{~m}$.

\section{Measurement methods}

Surface-layer measurements were made using the R/V CHESSIE as part of an effort by the U.S. Navy to study the evaporation duct. These measurements are described in more detail in Babin (1996b). The R/V CHESSIE, operated by The Johns Hopkins University Applied Physics Laboratory, is a 15 -m-long by 7 -m-wide research vessel. On either side of the boat, there was a mast with sensors at a height of $6 \mathrm{~m}$ above the sea surface. These sensors included a propeller-vane anemometer, a Rotronics capacitance polymer humidity sensor, a thermistor, and a conventional capacitive pressure transducer. To minimize boat effects, only the upwind $6-\mathrm{m}$ measurements were used in this study. The wind measurements were corrected for ship velocity and orientation. A third mast took measurements at a height of $10 \mathrm{~m}$ above the sea surface, well above the highest point on the boat $(3.6 \mathrm{~m})$. A kytoon (a balloon with fins for stabilization) tethered to the R/V CHESSIE made measurements at a height of $30 \mathrm{~m}$ above the sea surface.

Measurements of sea surface temperature and 2-cm air temperature and relative humidity were made using a $1.5-\mathrm{m}$ catamaran tethered $10 \mathrm{~m}$ from the boat in order to minimize contamination by the boat. The sea surface temperature was measured by a thermistor located approximately $2 \mathrm{~cm}$ below the sea surface. Air was drawn from a port located $2 \mathrm{~cm}$ above the surface into a chamber containing sensors for measuring temperature, humidity, and atmospheric pressure and thence through the driving fan and an exhaust port. Baffles in front of the ports helped prevent liquid water from entering the measurement chamber. The catamaran also had a mast for making measurements at heights of $1 \mathrm{~m}$ and $2 \mathrm{~m}$ above the ocean surface. The instrumentation and sensors are described in more detail by Meyer and Rowland (1990, 1991).

The atmospheric pressure was measured with a resolution of $0.1 \mathrm{hPa}$ and an accuracy of $3 \mathrm{hPa}$. Atmospheric and sea surface temperature were measured with a resolution of $0.1 \mathrm{~K}$ and an accuracy of $0.5 \mathrm{~K}$, and the relative humidity with a resolution of $1 \%$ and an accuracy of $2 \%$. The data were collected at a $2-\mathrm{Hz}$ rate and 5-min averages of the data were stored. There were 152 cases covering 29 days for which measurements at all heights were taken off the coast of Wallops Island, Virginia. These measurements covered a variety of seasons and weather conditions. The independence of these cases is discussed later.

During some of these Wallops Island measurements, microwave measurements were available from a nearby over-the-water transmission link described by Goldhirsh et al. (1994). Under certain conditions, it is possible to determine evaporation duct height from this microwave data. These evaporation duct height estimates will be used to check the validity of the duct heights determined from boat-measured profiles independent of the models.

All the evaporation duct models evaluated here were designed to be used over the open ocean. To see how they would behave in a very different environment, these models were compared using measurements from the tidal Potomac River near Dahlgren, Virginia. There were 56 cases covering 8 days of measurements. The $\mathrm{R} / \mathrm{V}$ CHESSIE was located at least $100 \mathrm{~m}$ from the closest shoreline, and conditions were always unstable, so that the lowest $10-30 \mathrm{~m}$ of the boundary layer should be adjusted to the river and can be considered horizontally homogeneous in the measurement area (Arya 1988; Hsu 1988).

\section{Results}

\section{a. Sensitivity analysis}

The sensitivity of the models to input sensor accuracy was compared using a Monte Carlo simulation (Babin 1996b). This analysis examines only the effects of random sensor errors and does not consider any ship-induced effects such as those described by Blanc (1986) and Cook (1991). Cook (1991) determined that duct height uncertainties due to random sensor errors alone may be 10\%-20\% less than those due to ship-induced distortions during the daytime. Cook (1991) also noted that these ship-induced distortions vary with the type of ship and the arrangement of the instrumentation. While the crew was careful to minimize ship-induced distortions, we did not estimate what they might be and we made no attempt to account for them in the following analysis.

Because the models perform different calculations for stable and unstable conditions, these two conditions were examined separately. Ten thousand runs of this Monte Carlo simulation were performed for each model separately for stable and unstable input conditions, and the results are shown in Tables 1 and 2, respectively.

For stable conditions, the following measured values were used: 6-m air temperature $3.8^{\circ} \mathrm{C}, 6-\mathrm{m}$ relative humidity $78.8 \%$, wind speed $7.98 \mathrm{~m} \mathrm{~s}^{-1}$, atmospheric pressure $1022.07 \mathrm{hPa}$, and sea surface temperature $2.0^{\circ}$. The following measured values were used for unstable conditions: 6-m air temperature $23.4^{\circ} \mathrm{C}, 6-\mathrm{m}$ relative hu- 
TABLE 1 . Stable case model sensitivity.

\begin{tabular}{lcc}
\hline \hline & Mean & $\begin{array}{c}\text { Standard } \\
\text { deviation }\end{array}$ \\
\hline Model A duct height (m) & 3.97 & 0.85 \\
MGB model duct height (m) & 6.15 & 8.22 \\
Paulus-Jeske (PJ) model duct height (m) & 5.28 & 0.74 \\
Jeske (J) model duct height (m) & 5.19 & 0.98 \\
\hline
\end{tabular}

midity $57.0 \%$, wind speed $3.66 \mathrm{~m} \mathrm{~s}^{-1}$, atmospheric pressure $1016.36 \mathrm{hPa}$, and sea surface temperature $24.8^{\circ} \mathrm{C}$. These atmospheric variables were allowed to vary randomly such that the mean was equal to these values and the standard deviation was equal to the sensor accuracy given by the manufacturer. The results of these 10000 runs were used to derive a mean duct height and its standard deviation for each model. The relative sensitivity of the models was determined from the relative sizes of these standard deviations in duct height.

For stable input conditions, the MGB model was the most sensitive model to input variable noise, followed by the $\mathrm{J}$ model, model $\mathrm{A}$, and the PJ model. For unstable input conditions, the $\mathrm{J}$ model was the most sensitive, followed by the MGB model, the PJ model, and model A. Note that the $J$ model (i.e., the PJ model without Paulus' input data modifications) showed greater sensitivity to noise than the PJ model. It should be kept in mind that, while the sensitivity of the models must be considered in any comparison, the least sensitive model is not necessarily the most accurate.

\section{b. Independent duct height determinations}

All evaporation duct models described here use only 6-m atmospheric measurements and sea surface temperature. To obtain a measurement of the evaporation duct height independent of the models, the following procedure was implemented. Using the boat measurements at all instrument heights $(0,0.02,1,2,6,10$, and $30 \mathrm{~m}$ ), a least-squares curve fit was applied to each of the 152 sets of measurements. This curve was based on a log-linear function given by

$$
M=f_{0} z-f_{1} \ln (z+0.001)+f_{2} .
$$

The constant 0.001 was added to prevent the curve from blowing up at zero altitude. For each case, the coefficients $f_{0}, f_{1}$, and $f_{2}$ were calculated for a least squares best fit. This function was then used to calculate values of modified refractivity $M$ for each $0.1 \mathrm{~m}$ between the surface and $100-\mathrm{m}$ altitude. The duct height was the height at which $M$ was a minimum.

As an additional check on the accuracy of these boatderived duct heights, eight cases were found for which boat measurements off Wallops Island coincided with the path of a $4.7-\mathrm{GHz}$ microwave link between two receivers on Assateague Island and a transmitter on Parramore Island. This link is described in more detail in Goldhirsh et al. (1994) and provides two line-of-sight
TABLE 2. Unstable case model sensitivity.

\begin{tabular}{lcc}
\hline \hline & Mean & $\begin{array}{c}\text { Standard } \\
\text { deviation }\end{array}$ \\
\hline Model A duct height (m) & 14.34 & 0.88 \\
MGB model duct height (m) & 17.38 & 2.33 \\
Paulus-Jeske (PJ) model duct height (m) & 18.64 & 1.54 \\
Jeske (J) model duct height (m) & 23.25 & 27.10 \\
\hline
\end{tabular}

over-the-water microwave links. Because the transmitted signal power is known, the fade in the received signal can be determined for each receiver.

By running the TEMPER electromagnetic propagation model (Dockery 1988), Goldhirsh et al. (1993) derived fade measurements for normal refraction with a superimposed evaporation duct at different heights. Time series fade measurements for each of the two receivers can then be examined to see how they compare to these simulations for the different evaporation duct heights. In this way, evaporation duct heights can be estimated from the fade measurements. Having the two receiver sites provides two estimates of evaporation duct height. The evaporation duct heights determined from the boat-derived data and the microwave link were found to be consistent with one another (Babin 1996b). We can conclude that these eight cases provide some evidence that the curve-fit procedure for determining duct height from boat profiles gives reasonable estimates of evaporation duct height.

This boat-derived duct height was then used as a basis for comparison with the model-predicted duct heights. Because the boat did not make any measurements above $30 \mathrm{~m}$, only boat-derived duct heights less than $30 \mathrm{~m}$ were used for comparison. This limit was imposed because an extrapolation of the least squares curve fit beyond $30 \mathrm{~m}$ was considered to be less reliable than the interpolation below $30 \mathrm{~m}$.

\section{c. Comparison of model duct heights with Wallops Island boat data}

Elimination of boat-derived duct heights greater than $30 \mathrm{~m}$ left 109 cases available for model comparison. Figures 2 through 5 show plots of the model-predicted duct height versus the boat-derived duct height for these cases. Root-mean-square (rms) errors were calculated to compare the model-predicted duct height with the boat-derived duct height for these cases and are presented in Table 3. The $F$ test (Nelson 1990) was used to determine whether the differences in rms errors for any two models were statistically significant. Based on these rms errors, there is a $99 \%$ probability that model $\mathrm{A}$ is the best model for the 109 cases compared, assuming each case is independent. These 109 measurements were made over 23 days. If only each day is assumed independent, then model $\mathrm{A}$ is the best model with a $94 \%$ confidence for these cases.

There are some cases in Fig. 5 for which model A 


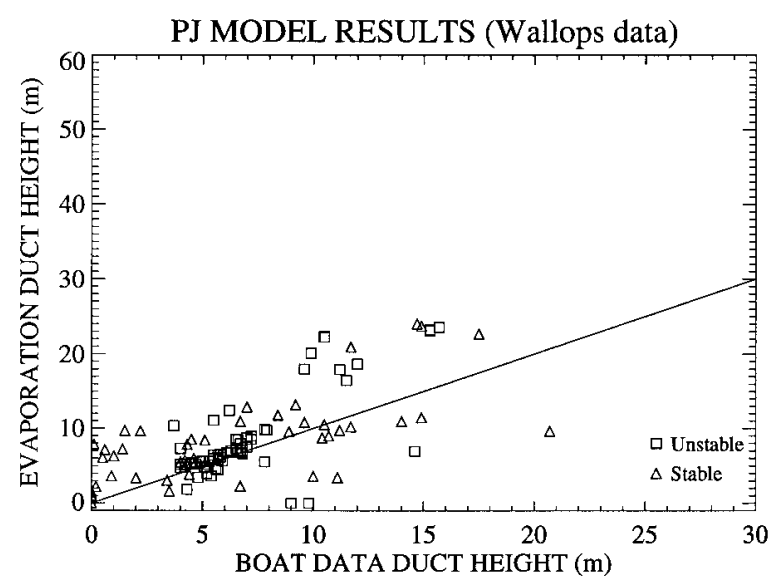

FIG. 2. Plot of PJ model duct height versus boat-derived duct height for the Wallops Island data. For reference, the solid line is the line of exact agreement (ordinate equals abscissa). The squares represent the unstable cases and the triangles represent the stable cases.

does not predict the boat duct height very well. Most of these cases had in common the fact that the curve fit to the boat-measured modified refractivity profile became almost vertical above $2 \mathrm{~m}$ (Babin 1996b). This could happen either because the profile actually was almost vertical up to an altitude above our maximum measurement height $(30 \mathrm{~m})$ or because our measurements were not at a fine enough scale to resolve the curvature. In either case, there will be an altitude above which the actual $M$ profile forms a positive vertical gradient. If the measurements accurately represent the $M$ profile, then the duct height would be the altitude just below where this vertical gradient changes from zero to a positive value. Therefore, cases for which the profile becomes nearly vertical over an extended altitude range would be very sensitive to measurement error. Mea-

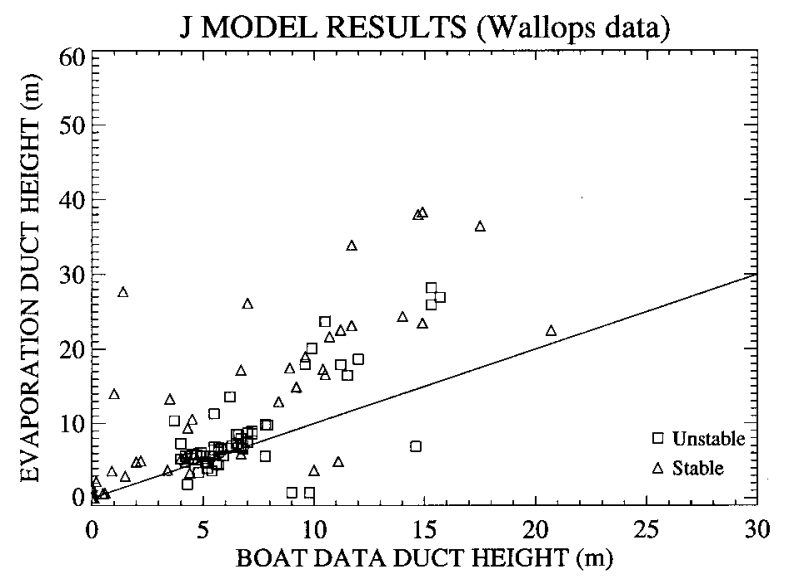

FIG. 3. Plot of J model duct height versus boat-derived duct height for the Wallops Island data. The $\mathbf{J}$ model is simply the PJ model without the ad hoc modifications to input data. For reference, the solid line is the line of exact agreement (ordinate equals abscissa). The squares represent the unstable cases and the triangles represent the stable cases.

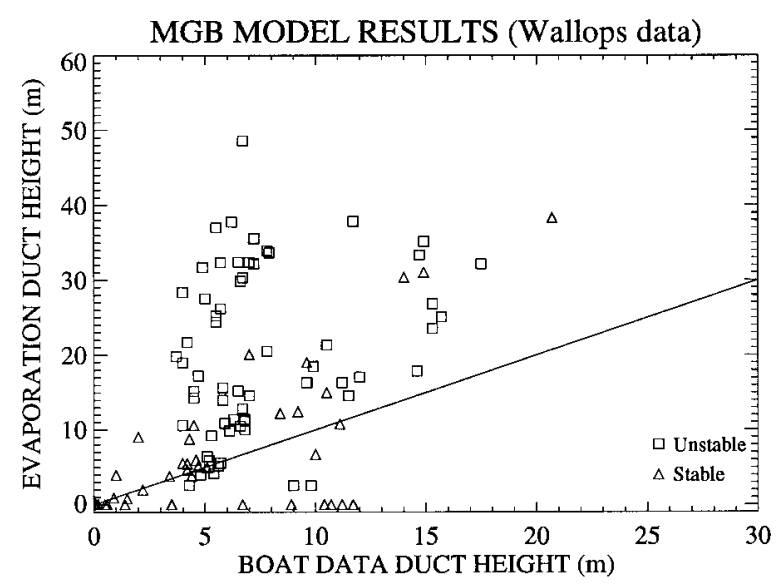

FIG. 4. Plot of MGB model duct height versus boat-derived duct height for the Wallops Island data. For reference, the solid line is the line of exact agreement (ordinate equals abscissa). The squares represent the unstable cases and the triangles represent the stable cases.

surements at additional intermediate altitudes and at higher altitudes would improve this curve fit. In addition, a detailed discussion of how well each model predicted the absolute refractivity value at each measurement height is given in Babin (1996b).

\section{d. Comparison of model duct heights with tidal Potomac boat data}

The R/V CHESSIE also made measurements while in the tidal Potomac River near Dahlgren, Virginia, in June and August of 1993. To test the models in this different environment, 56 cases were found for which the boatderived duct height did not exceed $30 \mathrm{~m}$. This represented eight days of data with seven measurements per day. It should be noted that the salinity correction, used by the MGB model and model A and applied to the

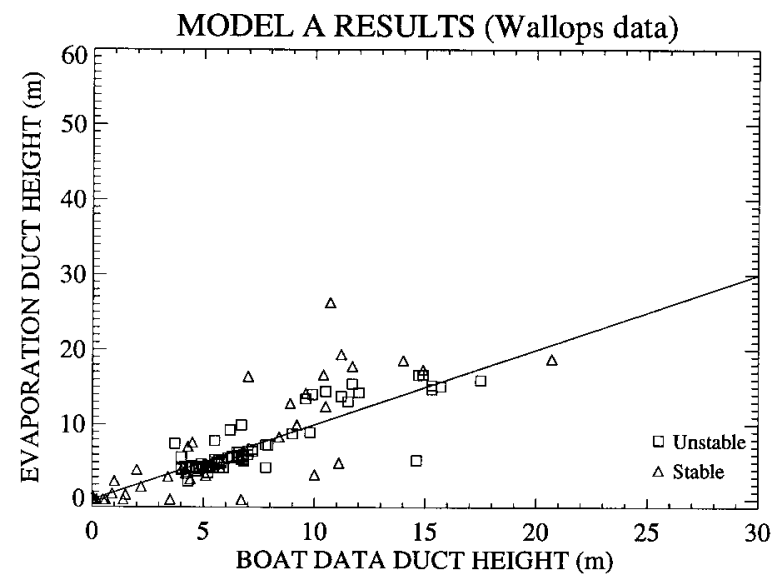

FIG. 5. Plot of model A duct height versus boat-derived duct height for the Wallops Island data. For reference, the solid line is the line of exact agreement (ordinate equals abscissa). The squares represent the unstable cases and the triangles represent the stable cases. 
TABLE 3. Comparison of Wallops Island boat data with model predictions.

\begin{tabular}{lc}
\hline \hline \multicolumn{1}{c}{ Model } & rms error $(\mathrm{m})$ \\
\hline Model A & 3.0 \\
MGB model & 13.1 \\
Paulus-Jeske (PJ) model & 4.3 \\
Jeske (J) model & 7.2 \\
\hline
\end{tabular}

Wallops Island data, was not used for the relatively freshwater tidal Potomac River. The PJ and J models do not include a salinity correction.

For these 56 cases, Figs. 6-9 show plots of the modelpredicted duct height versus the boat-derived duct height. Assuming each measurement is independent, there is a $99 \%$ probability that model $\mathrm{A}$ is the best predictor for these cases based on the $F$ test. Assuming only each day was independent, model A is the best model for these cases with a $90 \%$ level of confidence.

It is interesting to note that, when stability is defined by the Richardson number using ordinary temperatures (as in the PJ and J models), there appear to be both stable and unstable cases for the Dahlgren data. However, when either the Richardson number is defined using virtual temperatures (as in the MGB model) or when stability is defined by the Obukhov length (as in model A), all the Dahlgren cases are clearly unstable. This disparity illustrates the fact that using ordinary temperatures instead of virtual temperatures can be a serious enough error to change the sign of the Richardson number and thus the apparent stability.

\section{Summary and recommendations}

Certain meteorological conditions can cause anomalous propagation (nonstandard refraction) of electromagnetic radiation in the troposphere. A lack of consideration of these conditions can result in anomalous

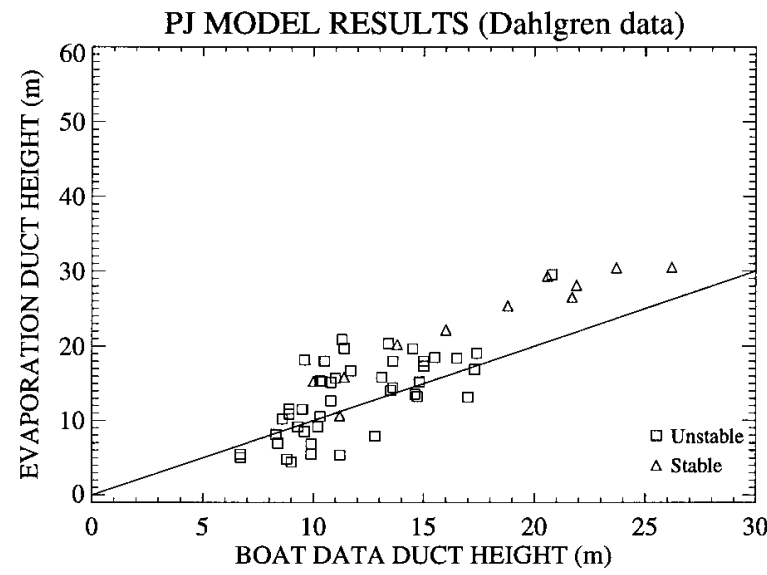

FIG. 6. Plot of PJ model duct height versus boat-derived duct height for the tidal Potomac River data. For reference, the solid line is the line of exact agreement (ordinate equals abscissa). The squares represent the unstable cases and the triangles represent the stable cases.

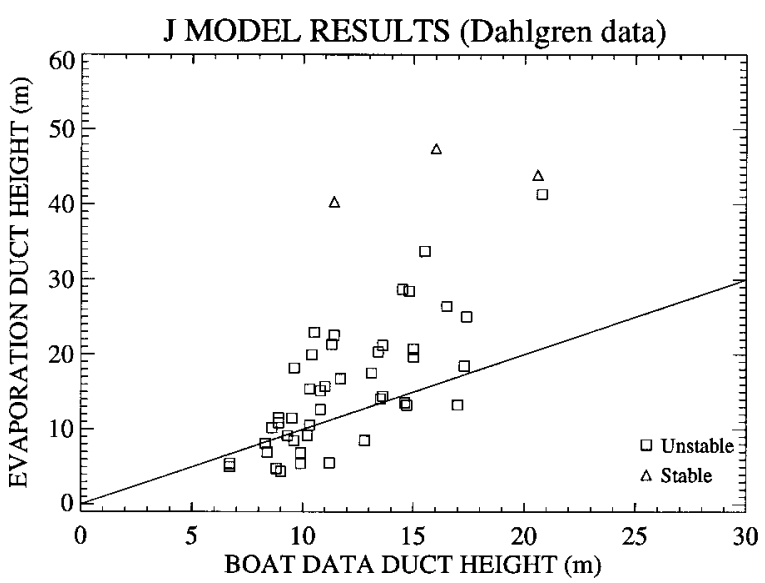

FIG. 7. Plot of $\mathbf{J}$ model duct height versus boat-derived duct height for the tidal Potomac River data. For reference, the solid line is the line of exact agreement (ordinate equals abscissa). The squares represent the unstable cases and the triangles represent the stable cases.

meteorological radar measurements. On the other hand, the development of highly sensitive radars can provide for the investigation of such phenomena as clear-air turbulence due to its association with nonstandard refraction.

Evaporation ducts are the most common cause of anomalous propagation over the ocean. These ducts tend to trap microwave and millimeter-wave electromagnetic radiation in a layer just above the ocean surface. This phenomenon thereby can affect radar sea surface reflectivity, ship- and shore-based radar, ship-to-ship and ship-to-shore communications, and ship-to-satellite communications at low grazing angles. The height of these ducts is the critical parameter for input into electromagnetic propagation models.

The current U.S. model (PJ) has been in operational

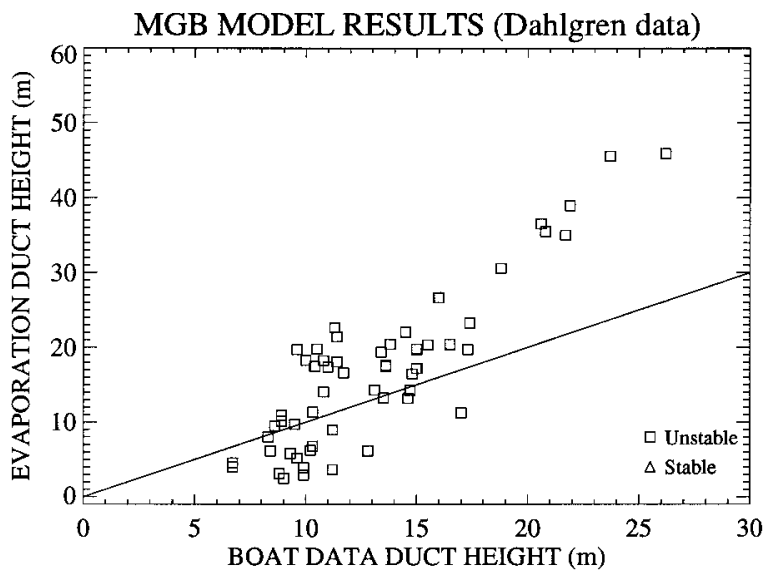

FIG. 8. Plot of MGB model duct height versus boat-derived duct height for the tidal Potomac River data. For reference, the solid line is the line of exact agreement (ordinate equals abscissa). The squares represent the unstable cases and the triangles represent the stable cases. 


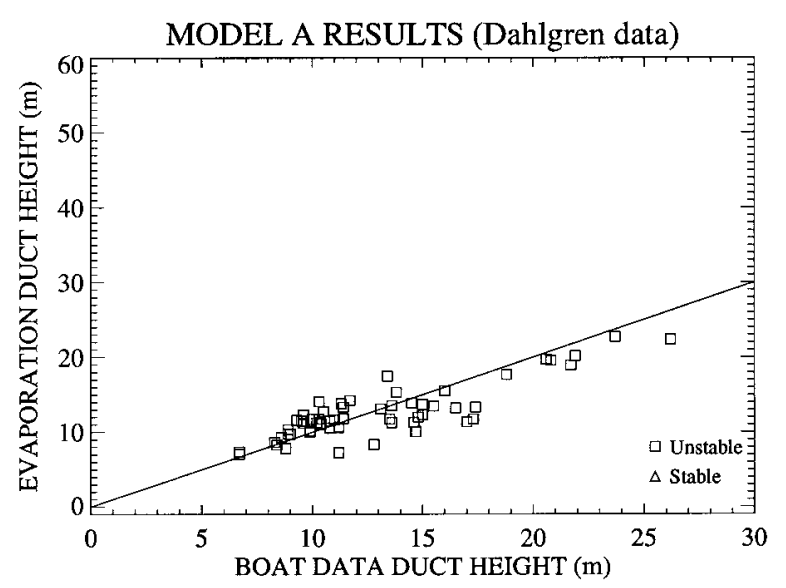

FIG. 9. Plot of model A duct height versus boat-derived duct height for the tidal Potomac River data. For reference, the solid line is the line of exact agreement (ordinate equals abscissa). The squares represent the unstable cases and the triangles represent the stable cases.

use by the U.S. Navy since 1978. This model is based on the premise that potential refractivity is a similarity variable. It also assumes an explicit empirical relationship between Obukhov length and bulk Richardson number. It uses an ad hoc method to correct air temperature measurements that are assumed to be in error, when in fact they may commonly occur under stable conditions in coastal areas. These and other problems with this model were discussed in detail above.

The current European model (MGB) is based more on traditional Monin-Obukhov similarity theory than the PJ model. Neither this model nor the PJ model provides a technique for extending Monin-Obukhov similarity to near zero wind speeds. The MGB model also relies on an implicit relationship between bulk Richardson number and Obukhov length that is derived from a set of data measured over the Norwegian Sea. On theoretical grounds, it appears to be an improvement over the PJ model. However, we have shown it to be highly sensitive to input variable noise. This limits its usefulness in an operational setting.

The proposed model (model A) uses the work of Godfrey and Beljaars (1991) to extend the validity of Monin-Obukhov similarity theory to low wind speeds. This model determines the Obukhov length iteratively without using the bulk Richardson number. The determination of the Monin-Obukhov parameters is based on a modified version of the algorithm used as a standard for bulk flux determinations in TOGA COARE. The TOGA COARE algorithm was developed to provide a surface energy budget determination with unprecedented accuracy and was verified with simultaneous flux and bulk measurements. Therefore, it is assumed that the Monin-Obukhov parameters determined by this method would provide a more accurate determination of evaporation duct height.

Another advantage of the new model is that it performs a sensitivity analysis for each set of input data.
This analysis is based on sensor inaccuracies input by the operator. In this paper, the sensor manufacturers' sensor inaccuracy was used because this information was readily available. If the operator had better estimates of random sensor inaccuracies, these values could be used instead. This sensitivity analysis should be used only for random errors and is not appropriate for systematic biases due to such factors as ship-induced effects. Nonetheless, the operator will not only get an evaporation duct height from this model, but also a standard deviation of duct heights based on the input sensor accuracy. This information will be of considerable value in that the operator will have an estimate of possible duct height error from sensor inaccuracies. This error estimate should greatly assist interpretation of the model's output duct height. For example, for an electromagnetic propagation model such as TEMPER, it is important to get the input duct height to within $2 \mathrm{~m}$ (Konstanzer 1994). Therefore, if the standard deviation from model A's sensitivity analysis were less than $2 \mathrm{~m}$, there would be more confidence in the predictions of the TEMPER model. None of the other models provide such an estimate.

It is very difficult to make direct microwave measurements of evaporation duct height (Patterson 1985). Data taken from measurements made off Wallops Island, Virginia, over a 2-yr period and a variety of seasons and conditions were used to compare these three models. Based on a comparison of the model-derived duct heights with independent duct height estimates from a least squares log-linear curve fit to the boat profile measurements, model A provided a statistically significant improvement in accuracy. The models were developed for use over the ocean. To test these models in a very different environment, use was made of boat measurements in the tidal Potomac River off Dahlgren, Virginia. It was shown that, even in this environment, the new model performs significantly better than the other models.

While it is superior to the other models in the cases examined, model A does have areas where it can be improved. The most serious problem with model A is that it assumes horizontal homogeneity in the boundary layer. Horizontal homogeneity may not always be a valid assumption very close (e.g., less than $100 \mathrm{~m}$ ) to the shore. However, any model that uses Monin-Obukhov similarity theory would have the same problem.

Future experiments should be performed to more completely validate the models. Measurements should be made at finer altitude intervals than those described here in order to improve the curve fit. Because the greatest changes occur close to the surface, measurements should be made at as many altitudes below $10 \mathrm{~m}$ as possible. It would be advantageous if the temperature and moisture fluxes could be measured independently of the bulk measurements. These experiments should include simultaneous microwave and meteorological measurements. Because conditions with surface ducts 
based on temperature inversions could overwhelm any evaporation duct effects (e.g., Babin and Rowland 1992), the microwave validation data should be taken only during conditions when such surface ducts are absent. This can be determined using vertical refractivity profile measurements made by rocketsonde as described in Rowland and Babin (1987) or by helicopter as described in Babin and Rowland (1992). For similar reasons, data taken during subrefractive conditions should be excluded. The result of such an experimental validation will provide an evaporation duct model that would be valuable to the radar meteorology community.

Acknowledgments. The authors would like to express their gratitude to Chris Fairall of the NOAA Environmental Technology Laboratory for many valuable suggestions. The authors would also like to thank Richard Paulus of the U.S. Naval Command, Control, and Ocean Surveillance Center for his comments. Many thanks to Dan Dockery and Julius Goldhirsh of The Johns Hopkins University Applied Physics Laboratory for providing the atmospheric and microwave data used in the comparisons. JAC was supported by the National Science Foundation under Grant OCE9416894.

\section{REFERENCES}

Almond, T., and J. Clarke, 1983: Consideration of the usefulness of microwave propagation prediction methods on air-to-ground paths. Proc. IEE, Part F, 130, 649-656.

Anderson, K. D., 1989: Radar measurements at $16.5 \mathrm{GHz}$ in the oceanic evaporation duct. IEEE Trans. Antennas Propag., 37, 100-106.

- 1990: 94-GHz propagation in the evaporation duct. IEEE Trans. Antennas Propag., 38, 746-753.

Anderson, L. J., and E. E. Gossard, 1953a: The effect of the oceanic duct on microwave propagation. Trans. Amer. Geophys. Union, 34, 695-700.

- and - 1953b: Oceanic duct and its effect on microwave propagation. Nature, 172, 298-300.

Arya, S. P., 1988: Introduction to Micrometeorology. Academic Press, $303 \mathrm{pp}$

Babin, S. M., 1995: A case study of sub-refractive conditions at Wallops Island, Virginia. J. Appl. Meteor., 34, 1028-1038.

_ 1996a: Surface duct height distributions for Wallops Island, Virginia, 1985-1994. J. Appl. Meteor., 35, 86-93.

— 1996b: A new model of the oceanic evaporation duct and its comparison with current models. Ph.D. dissertation, University of Maryland, $190 \mathrm{pp}$. [Available from University Microfilm, 305 N. Zeeb Rd., Ann Arbor, MI 48106.]

— and J. R. Rowland, 1992: Observation of a strong surface radar duct using helicopter acquired fine-scale radio refractivity measurements. Geophys. Res. Lett., 19, 917-920.

Baumgartner, G. B., Jr., H. V. Hitney, and R. A. Pappert, 1983: Duct propagation modeling for the integrated-refractive-effects prediction system (IREPS). Proc. IEE, Part F, 130, 630-642.

Bean, B. R., and E. J. Dutton, 1968: Radio Meteorology. Dover Publications, $435 \mathrm{pp}$.

Blanc, T. V., 1986: The effect of inaccuracies in weather-ship data on bulk-derived estimates of flux, stability, and sea-surface roughness. J. Atmos. Oceanic Technol., 3, 12-26.

Borsum, D. L., 1995: Doppler dilemma delineates danger from dirt. National Weather Service Western Region Tech. Attachment 95-07, 7 pp. [Available from National Weather Service Field
Office, DOC/WASC, 3833 S. Development Ave., \#3807, Boise, ID 83705-5354.]

Brutsaert, W., 1991: Evaporation into the Atmosphere: Theory, History, and Applications. Kluwer Academic Publishers, 299 pp.

Buck, A. L., 1981: New equations for computing water vapor pressure and enhancement factor. J. Appl. Meteor., 20, 1527-1532.

Businger, J. A., J. C. Wyngaard, Y. Izumi, and E. F. Bradley, 1971: Flux-profile relationships in the atmospheric surface layer. $J$. Atmos. Sci., 28, 190-201.

Cook, J., 1991: A sensitivity study of weather data inaccuracies on evaporation duct height algorithms. Radio Sci., 26, 731-746.

, and S. Burk, 1992: Potential refractivity as a similarity variable. Bound.-Layer Meteor., 58, 151-159.

Debye, P. J. W., 1929: Polar Molecules. The Chemical Catalog Co., $172 \mathrm{pp}$.

Dockery, G. D., 1988: Modeling electromagnetic wave propagation in the troposphere using the parabolic equation. IEEE Trans. Antennas Propag., 36, 1464-1470.

Douchin, N., S. Bolioli, F. Christophe, and P. Combes, 1994: Theoretical study of the evaporation duct effects on satellite-to-ship radio links near the horizon. IEE Proc. Part H, Microwaves, Antennas Propag., 141, 272-278.

Fairall, C. W., K. L. Davidson, G. E. Schacher, and T. M. Houlihan, 1978: Evaporation duct height measurements in the mid-Atlantic. Naval Postgraduate School Final Rep. NPS61-78-005 and Naval Oceanographic Office Tech. Rep. TR256, 137 pp. [Available as AD \#A060451 from Defense Technical Information Center, Cameron Station, Alexandria, VA 22304-6145.]

— - E. F. Bradley, D. P. Rogers, J. B. Edson, and G. S. Young, 1996: Bulk parameterization of air-sea fluxes for Tropical Ocean-Global Atmosphere Coupled-Ocean Atmosphere Response Experiment. J. Geophys. Res., 101(C2), 3747-3764.

Geleyn, J. F., 1988: Interpolation of wind, temperature, and humidity values from model levels to the height of measurements. Tellus, 40A, 347-351.

Godfrey, J. S., and A. C. M. Beljaars, 1991: On the turbulent fluxes of buoyancy, heat, and moisture at the air-sea interface at low wind speeds. J. Geophys. Res., 96(C12), 22 043-22 048.

Goldhirsh, J., G. D. Dockery, and B. H. Musiani, 1993: Three years of $\mathrm{C}$ band fade statistics for over-water, line of sight links in the mid-Atlantic coast. JHU/APL Tech. Rep. S1R-93U-018, 87 pp. [Available from The Johns Hopkins University, Applied Physics Laboratory, Laurel, MD 20723.]

,-- , and — -1994 : Three years of $\mathrm{C}$ band signal measurements for overwater, line-of-sight links in the mid-Atlantic coast. Part 1: Fade statistics. Radio Sci., 29, 1421-1431.

Hitney, H. V., and J. H. Richter, 1976: Integrated refractive effects prediction system (IREPS). Nav. Eng. J., 88, 257-262.

—, and R. Vieth, 1990: Statistical assessment of evaporation duct propagation. IEEE Trans. Antennas Propag., 38, 794-799.

Hsu, S. A., 1988: Coastal Meteorology. Academic Press, 260 pp.

Jeske, H., 1973: State and limits of prediction methods of radar wave propagation conditions over the sea. Modern Topics in Microwave Propagation and Air-Sea Interaction, A. Zancla, Ed., D. Reidel Publishing, 130-148.

Kaimal, J. C., and J. C. Wyngaard, 1990: The Kansas and Minnesota experiments. Bound.-Layer Meteor., 50, 31-47.

Katzin, M., R. W. Bauchman, and W. Binnian, 1947: 3- and 9-centimeter propagation in low ocean ducts. Proc. IRE, 35, 891-905.

Kiefer, P. J., 1941: The thermodynamic properties of water and water vapor. Mon. Wea. Rev., 69, 329-331.

Konstanzer, G. C., 1994: Sensitivity of AN/SPY-1B propagation to evaporation duct heights. JHU/APL Tech. Rep. F2F-94-U-4-012, 34 pp. [Available from The Johns Hopkins University, Applied Physics Laboratory, Laurel, MD 20723.]

Liu, W. T., K. B. Katsaros, and J. A. Businger, 1979: Bulk parameterization of air-sea exchanges of heat and water vapor including the molecular constraints at the interface. J. Atmos. Sci., 36, $1722-1735$ 
Louis, J. F., 1979: A parametric model of vertical eddy fluxes in the atmosphere. Bound.-Layer Meteor., 17, 187-202.

Meyer, J. H., and J. R. Rowland, 1990: An instrumentation SLED for measurement of near ocean surface temperature, humidity, and water temperature. MTS '90 Science and Technology for a New Ocean Decade Conf. Proc., Vol. 2, Washington, DC, Marine Technology Society, 489-494.

- and - 1991: Instrumentation for probing the air-water interface. Oceans '91 Conf. Proc., Honolulu, HI, Oceanic Engineering Society of the IEEE, 1-10. [Reprints available from J. H. Meyer, The Johns Hopkins University, Applied Physics Laboratory, Johns Hopkins Road, Laurel, MD 20723-6099.]

Monin, A. S., and A. M. Obukhov, 1954: Basic laws of turbulent mixing in the atmosphere near the ground. Tr. Geofiz. Inst., Akad. Nauk SSSR, 24, 163-187.

Moszkowicz, S., G. J. Ciach, and W. F. Krajewski, 1994: Statistical detection of anomalous propagation in radar reflectivity patterns. J. Atmos. Oceanic Technol., 11, 1026-1034.

Musson-Genon, L., S. Gauthier, and E. Bruth, 1992: A simple method to determine evaporation duct height in the sea surface boundary layer. Radio Sci., 27, 635-644.

Nelson, P. R., 1990: Design and analysis of experiments. Handbook of Statistical Methods for Engineers and Scientists, H. M. Wadsworth, Ed., McGraw Hill Publishing, 4.15 and 14.12-14.14.

Patterson, W. L., 1985: Comparison of evaporation duct and path loss models. Radio Sci., 20, 1061-1068.

Paulus, R. A., 1984: Practical application of the IREPS evaporation duct model. NOSC Tech. Rep. 966, 68 pp. [Available from National Technical Information Service, U.S. Department of Commerce, Technology Administration, 5285 Port Royal Road, Springfield, VA 22161.]
- 1985: Practical application of an evaporation duct model. Radio Sci., 20, 887-896.

— 1989: Specification for environmental measurements to assess radar sensors. NOSC Tech. Document 1685, 43 pp. [Available from National Technical Information Service, U.S. Department of Commerce, Technology Administration, 5285 Port Royal Road, Springfield, VA 22161.]

— 1990: Evaporation duct effects on sea clutter. IEEE Trans. Antennas Propag., 38, 1765-1771.

Reilly, J. P., and G. D. Dockery, 1990: Influence of evaporation ducts on radar sea return. Proc. IEE, Part F, 137, 80-88.

Rogers, R. R., and M. K. Yau, 1989: A Short Course in Cloud Physics. $3 d$ ed. Pergamon Press, 293 pp.

Rowland, J. R., and S. M. Babin, 1987: Fine-scale measurements of microwave refractivity profiles with helicopter and low-cost rocket probes. Johns Hopkins APL Tech. Dig., 8, 413-417.

Stull, R. B., 1991: An Introduction to Boundary Layer Meteorology. Kluwer Academic Publishers, 666 pp.

Sverdrup, H. U., M. W. Johnson, and R. H. Fleming, 1942: The Oceans: Their Physics, Chemistry, and General Biology. Prentice-Hall, $1087 \mathrm{pp}$.

Webster, P. J., and R. Lukas, 1992: TOGA COARE: The Coupled Ocean Atmosphere Response Experiment. Bull. Amer. Meteor. Soc., 73, 1377-1416.

Wieringa, J., 1980: A reevaluation of Kansas mast influence on measurements of stress and cup anemometer over-speed. Bound.Layer Meteor., 18, 411-430.

- , 1982: Reply. Bound.-Layer Meteor., 22, 251-255.

Wyngaard, J. C., J. A. Businger, J. C. Kaimal, and S. E. Larsen, 1982: Comments on "A revaluation of the Kansas mast influence on measurements of stress and cup anemometer overspeeding." Bound.-Layer Meteor., 22, 245-250. 